\title{
Regimen Used to Treat Malignant Reproductive Endocrine Neoplasm
}

National Cancer Institute

\section{Source}

National Cancer Institute. Regimen Used to Treat Malignant Reproductive Endocrine

Neoplasm. NCI Thesaurus. Code C159910.

Any regimen that can be used to treat malignant reproductive endocrine neoplasm. 